\title{
REDUÇÃO DE FOCOS DE Aedes aegypti POR MEIO DE AÇÕES DE EDUCAÇÃO AMBIENTAL NO MUNICÍPIO DE CONDOR (RS)
}

Taís Rahmeier ${ }^{1}$

Resumo: O trabalho apresenta uma pesquisa-ação realizada no município de Condor, Rio Grande do Sul, e tem como objeto de estudo ações de Educação Ambiental voltadas para a sensibilização da população, visando a redução dos focos do mosquito Aedes aegypti. O diagnóstico foi realizado através da comparação de dados retirados dos registros do SINAN e LIRAa, onde podemos observar dados relativos a quantidade de casos suspeitos $\mathrm{e}$ confirmados de dengue, assim como os índices de infestação do mosquito $A$. aegypti. Os resultados obtidos demonstraram a importância da Educação Ambiental como ferramenta transformadora, contribuindo para a participação coletiva na melhoria da qualidade de vida de toda população.

Palavras-chave: Sensibilização; Ações de Educação Ambiental; Resíduos Sólidos; Vetores; Aedes aegypti. 


\section{Introdução}

A deposição de resíduos em locais inadequados causa impactos no meio ambiente e aos seres humanos, já que a decomposição dos materiais gera substâncias altamente tóxicas que irão contaminar o solo, a água e o ar, podendo atingir todos os seres vivos que constituem esse ecossistema, além de se tornar um ambiente propício para o desenvolvimento de espécies de animais que se tornam vetores e acabam por transmitir doenças aos seres humanos. Esta prática de efeitos incontroláveis apresenta custos cada vez mais elevados para a adoção de medidas de controle e para a saúde pública.

Atualmente uma das maiores preocupações da saúde pública no Brasil, são as epidemias, ou seja, doenças infecciosas que acometem um grande número de pessoas em uma determinada localidade. Ainda mais alarmante é quando o transmissor da doença em questão trata-se de um inseto de fácil proliferação, como é o caso do mosquito da espécie Aedes aegypti, transmissor de doenças como a dengue, febre chikungunya e zika vírus.

Em vários países do mundo, principalmente os de clima temperado ou tropical, ocorrem epidemias de doenças causadas por este vetor, o qual está sendo considerado um dos grandes vilões para a saúde dos seres humanos. De hábitos diurnos, o $A$. aegypti, põem seus ovos, principalmente durante as estações quentes, em pequenas poças de água, os quais eclodem liberando larvas que se tornarão mosquitos adultos, que se alimentam de sangue. Ao picar uma pessoa infectada com o vírus de uma das três doenças já citadas, este torna-se um vetor, o qual passará o vírus para cada pessoa que picar.

Visando a sensibilização da população diante do aumento de focos do mosquito $A$. aegypti, a equipe da Secretaria Municipal de Saúde do Município de Condor/RS, promoveu ações de Educação Ambiental como forma de minimizar os altos índices de infestação do mosquito, que vinham se apresentando. Desta forma, buscou-se nas ações de Educação Ambiental uma forma de prevenir as epidemias e proliferação do $A$. aegypti, por meio do engajamento da comunidade em ações direcionadas à sensibilização da importância de se preservar o ambiente como garantia para a promoção da saúde e qualidade de vida da população.

\section{Desenvolvimento}

As epidemias são um grande problema para toda população em todos os países do mundo, porém nos países de temperaturas mais elevadas uma espécie de mosquito se destaca o Aedes aegypti, o qual pode se proliferar em pequenas poças de água, e faz dos resíduos sólidos condicionados de forma inadequada seu principal foco de reprodução. Desta forma, este trabalho tem como principal objetivo colocar em prática ações de Educação Ambiental, visando sensibilizar e mobilizar a comunidade do município de Condor (RS), quanto à prevenção e diminuição de focos do mosquito Aedes aegypti. 


\section{Revisão Bibliográfica}

Os resíduos sólidos podem ser definidos, segundo a Política Nacional dos Resíduos Sólidos (2010), como quaisquer materiais que sobrem no estado sólido e que resultam de atividades de origem urbana, industrial, de serviços de saúde, rural, especial ou diferenciada. Portanto, os resíduos sólidos são exclusivamente resultantes das atividades humanas no meio em que estão inseridos.

De acordo com o Panorama dos Resíduos Sólidos no Brasil de 2015, só no estado do Rio Grande do Sul se produz, por dia, em média $0,731 \mathrm{~kg}$ de resíduos sólidos por habitante, o que resulta em torno de 8.224 toneladas de resíduos sólidos diários, que infelizmente em sua maior parte vai parar em lixões e aterros. Estima-se que o ambiente doméstico inadequado é responsável por quase $30 \%$ da ocorrência de doenças nos países em desenvolvimento.

O que relaciona os resíduos sólidos com o mosquito Aedes aegypti, é a sua má disposição. Ao deixar os resíduos sólidos acumulados nos pátios, ou em deposição equivocada em beiras de estradas e terrenos baldios, sem 0 acondicionamento adequado, evidencia-se "um problema de saúde pública e a degradação do meio ambiente" (PAIVA; SILVA; AGUIAR, 2012, p.1).

Conforme Paiva, Silva e Aguiar (2012), adaptado ao meio urbano, o mosquito $A$. aegypti encontrou nos resíduos sólidos um local de proliferação, onde consegue por seus ovos.

Assim acaba-se por relacionar os resíduos sólidos às epidemias de dengue, chikungunya e zika vírus, visto que eles estão entre os principais criadouros do mosquito Aedes aegypti, pois estando mal acondicionados acumulam água, proporcionando sua infestação e consequentemente aumenta o número de pessoas infectadas.

Segundo o Levantamento Rápido do Índice de Infestação por Aedes aegypti (LIRAa),sistema que mapeia os índices de infestação do mosquito no país, no ano de 2015, 199 municípios brasileiros estavam em situação de risco de surto de dengue, chikungunya e zika. Isso significa que mais de $4 \%$ das casas visitadas nestas cidades continham larvas do mosquito. Para a prevenção de epidemias e do aumento no índice de infestação, assim como no número de focos do $A$. aegypti, precisa-se

intervir junto aos determinantes da doença, como o lixo, com o intuito de modificar as condições ambientais, os contextos sociais e outros fatores que favoreçam a proliferação de vetores, utilizando abordagens participativas multisetoriais para a sustentabilidade em longo prazo (MIRANDA et al, 2013, p. 234) 
O Rio Grande do Sul está em constante risco de epidemias, pois as mudanças climáticas e a elevação da temperatura são fatores favoráveis ao desenvolvimento do vetor $A$. aegypti (PES 2016-2019, 2016), e mesmo sendo uma região onde as estações anuais são bem marcadas, os ovos resistentes desta espécie de mosquito, o faz suportar a rigorosa diminuição das temperaturas no inverno (FORATTINI, 1965 apud JÚNIOR; BERNARDES, 1999, p. 3952), ou seja, mesmo que o ciclo de vida do mosquito ocorra em períodos de temperatura elevada, os ovos que não eclodiram permanecem resistentes durante as temperaturas frias, para liberar as larvas assim que haja condições favoráveis de vida.

De acordo com o Plano Estadual de Saúde 2016-2019 (PES 20162019, 2016), o estado do Rio Grande do Sul registrou no período de 2012 até 2015, um aumento de 79 para 174 municípios infestados pelo mosquito $A$. aegypti, sendo que destes municípios destacam-se em número de casos de dengue, zika e chikungunya, os localizados na região noroeste do Estado. Neste período, houve epidemias de dengue em vários municípios vizinhos ao município de Condor, sendo que em dois deles foram registrados casos de óbitos.

No município de Condor, no ano de 2016, no período de janeiro a junho, houve diminuição no índice de infestação por $A$. aegypti, onde foi registrado $50 \%$ de redução da infestação comparado ao mesmo período no ano de 2015 (LIRAa), porém, dos 31 casos suspeitos de dengue, 8 foram confirmados positivos (Sistema de Informação de Agravos de Notificação SINAN), ou seja, em 2016 já haviam mosquitos contaminados com o vírus causador dos sintomas de dengue no município.

As epidemias de dengue, chikungunya e zika são problemas de alta complexidade, pois a proliferação do $A$. aegypti é facilitada pela falta de cuidado com recipientes de uso doméstico que acumulam água, assim como a má disposição de resíduos sólidos, os quais também acumulam água e acabam sendo abandonados ao redor dos pátios, terrenos baldios e beiras de ruas e estradas, se tornando locais convenientes para que $\circ A$. aegypti coloque seus ovos.

Desta forma, a solução para prevenir o surgimento de epidemias requer "medidas que extrapolam a área da saúde, exigindo mobilização das diferentes esferas de governo, especialmente do saneamento e educação, bem como de toda sociedade" (PES 2016-2019, 2016, p. 42). A Educação Ambiental é um processo informativo e formativo dos indivíduos, a qual desenvolve habilidades e modifica as atitudes dos seres humanos em relação ao meio ambiente, tornando a comunidade consciente de sua realidade global. Um programa de Educação Ambiental eficiente deve promover, simultaneamente, o desenvolvimento de conhecimento, de atividades e de habilidades necessárias à preservação e melhoria da qualidade ambiental (DIAS, 1992). Trabalhar a Educação Ambiental engloba a sensibilização para a tomada de consciência sobre a urgência em preservar o meio ambiente, somando um conjunto de valores que devem ser transmitidos tanto nas salas Revbea, São Paulo, V. 14, № 2: 165-176, 2019. 
de aula (educação formal), como dentro das comunidades e famílias (educação informal).

A educação, assim como a Educação Ambiental têm a "capacidade de promover valores, não sendo somente um meio de transmitir informações $e$ trata-se de um processo que envolve transformações no sujeito que aprende $e$ incide sobre sua identidade e posturas diante do mundo" (MEDEIROS et al., p. 16, 2011). O desenvolvimento de habilidades com a inserção de maior cooperação aumenta as expectativas de ampliar os resultados pretendidos.

Ainda para Medeiros et al. (2011), é através de muitos argumentos, desenvolvimento de atividades e experimentos que se consegue conscientizar grupos. Pode-se então compreender que as atividades que se iniciam sensibilizando as crianças sobre as preocupações ambientais, expandem-se para fora da escola e são transmitidas as suas famílias, mobilizando grupos cada vez maiores.

A participação de toda a comunidade no controle da proliferação do mosquito é considerada fundamental. Portanto, entre os desafios da Educação Ambiental, está a criação e o aperfeiçoamento de técnicas e ações de intervenção, as quais venham contribuir de forma efetiva na redução da infestação pelo mosquito $A$. aegypti (CAVALCANTE et al., 2007).

\section{Metodologia}

O trabalho aqui apresentado trata-se de uma pesquisa-ação a qual é "um tipo de pesquisa com base empírica que é concebida e realizada em estreita associação com uma ação ou com a resolução de um problema coletivo" (THIOLLENT, 1986, p. 14). A pesquisa-ação parte de uma situação social concreta que deve ser modificada, sendo que os pesquisadores e participantes representativos do problema se envolvem no trabalho de modo cooperativo ou participativo.

Este trabalho foi realizado no município de Condor, localizado na região Noroeste do estado do Rio Grande do Sul. De acordo com o Instituto Brasileiro de Geografia e Estatística - IBGE (2010), a população do município é de 6.552 habitantes, tendo uma área de $465,188 \mathrm{~km}^{2}$ sendo a densidade demográfica de 14,1 habitantes por $\mathrm{km}^{2}$ no território do município.

As ações de Educação Ambiental desenvolvidas no município de Condor/RS ocorreram na segunda quinzena do mês de novembro do ano de 2016, período em que há elevação na temperatura e as condições de proliferação do mosquito Aedes aegypti são mais favoráveis (ou propícias).

As ações realizadas foram: palestras, caminhada ecológica, pedágio ecológico e mutirão de limpeza de pátios e terrenos. Estas ações tiveram início com alunos do ensino fundamental, de escolas municipais e estaduais do município, nas quais foram realizadas palestras informativas sobre o vetor $A$. aegypti, a prevenção de focos de proliferação do mosquito e as doenças que podem ser transmitidas por ele.

revista brasileira educação ambiental 


\section{Resultados e Discussão}

As ações de Educação Ambiental praticadas no município de Condor tiveram início com os alunos dos anos iniciais das escolas municipais e estaduais, visando que no momento em que estes são estimulados e sensibilizados pela Educação Ambiental acabem por colocar em prática as ações dentro das instituições de ensino e também passem a transmiti-las a suas famílias, gerando assim um trabalho amplo de sensibilização e ação dentro da comunidade em que estão inseridos.

Durante a realização das palestras observou-se a ampla participação dos alunos durante as falas dos agentes de vigilância ambiental, os quais questionavam e tinham interesse em participar, contando experiências vividas por seus familiares ou vizinhos.

Apesar da pouca idade dos alunos, a partir dos 7 anos ( $2^{\circ}$ ao $5^{\circ}$ ano do ensino fundamental), todos participaram e observaram com muita atenção o material levado pelos palestrantes. Após a palestra, houve troca de ideias e experiências, o que foi muito enriquecedor, pois neste momento surgiram dúvidas que foram sanadas pelos palestrantes, e os alunos puderam se expressar. Também se pode observar a importância da Educação Ambiental nas escolas, onde os alunos têm o poder e dever de participar, sendo ouvidos e realizando ações para o bem comum, mostrando-lhes que estão inseridos no âmbito social, e que fazem parte da comunidade e desta forma, são também responsáveis pela preservação do meio ambiente.

De acordo com Gadotti (2009), atualmente há mais de um bilhão de crianças e jovens inseridos em instituições de ensino em todo o mundo, e uma mudança realizada em seus estilos de vida, informações colocadas em prática, e a sensibilização transformada em ação, faria uma grande diferença para o meio ambiente, pois estes são importantes membros na disseminação de informação.

Durante a caminhada ecológica, as crianças conversavam com alguns pedestres e até mesmo faziam paradas rápidas em estabelecimentos comerciais, visando convidar a comunidade para participar da retirada de resíduos sólidos dispostos em locais impróprios.

As crianças orientavam a população a auxiliar na redução de focos de proliferação do mosquito, juntavam resíduos que encontravam durante o caminho e compartilhavam as informações que lhes foram repassadas durante as palestras. Nesse momento, os alunos aproveitavam para conversar rapidamente com a população, alertando sobre os riscos de epidemias que a infestação de $A$. aegypti pode causar.

Ainda na caminhada ecológica foram utilizados banners e faixas com mensagens de sensibilização ao combate do mosquito $A$. aegypti, assim como pequenas frases com dicas de como eliminar possíveis focos de proliferação do mosquito. É através de mobilizações como esta que a Educação Ambiental 
atua unindo os diferentes atores da sociedade em torno de objetivos comuns de transformação tanto de conceitos como também da prática ambiental, contribuindo na prevenção e solução dos problemas ambientais, aumentando a qualidade de vida (VALDAMERI, 2004).

A mudança de alguns hábitos da população pode vir a reduzir muito os níveis de infestação do $A$. aegypti, de acordo com Ferreira et al (2009), a participação da comunidade e a mobilização da população são importantes contribuintes para a prevenção de doenças epidêmicas nas áreas urbanas. As ações realizadas no pedágio ecológico visavam algumas dessas mudanças de hábitos.

Infelizmente é muito comum encontrar-se resíduos sólidos jogados em beiras de estrada e ruas, muitas vezes conseqüência de um ato inconsciente de um motorista, passageiro ou até mesmo pedestre, de descartar resíduos em locais inapropriados.

A distribuição dos saquinhos de lixo para automóveis foi uma forma de prevenir este ato e ainda lembrar a população dos perigos causados pela elevação de infestação de $A$. aegypti, assim como lembrá-los de que pequenos atos e mudanças de hábitos podem prevenir de forma eficiente a proliferação do mosquito.

Assim como a caminhada ecológica, o pedágio chamou a atenção da população em geral, e os motoristas aderiram bem ao pedágio, respeitando quando o automóvel era parado e ouvindo com atenção as dicas dos agentes de saúde e agentes ambientais que estavam nos pontos de pedágio. Cazola et al. (2011), ressaltam que para a prevenção da proliferação de $A$. aegypti, são necessárias mudanças no comportamento da população, sendo que estas mudanças devem estar associadas a sua percepção com o problema.

Durante o pedágio ecológico pode-se observar o interesse das pessoas em saber mais sobre a ação que estava sendo realizada, assim através da sensibilização e da adoção de novos hábitos se torna mais fácil de evitar a presença e reprodução do mosquito $A$. aegypti, pois estes novos hábitos se transformam em ações incorporadas no cotidiano.

O ponto culminante do trabalho foi a realização de um mutirão, onde toda a comunidade e o poder público se uniram para reduzir os possíveis focos de $A$. aegypti. Todas as ações anteriores foram elaboradas visando 0 chamamento da população do município para aderir ao mutirão. A sensibilização quanto às doenças que o vetor $A$. aegypti pode transmitir, as consequências da disposição inadequada dos resíduos sólidos e a busca pela interação da comunidade tiveram seus resultados refletidos no mutirão, onde a grande maioria dos habitantes participou. Foram recolhidos vários tipos de resíduos sólidos, desde tampinhas de garrafas até restos de materiais de construção civil.

Cada morador foi convidado a limpar seus pátios e entorno, retirando das beiradas de ruas e terrenos baldios resíduos que pudessem acumular água

revista brasileira educação ambiental 
e ser utilizados pelo mosquito como local de desova, ou seja, um possível foco de $A$. aegypti.

O acúmulo de resíduos sólidos e a manifestação de casos de dengue, zika vírus e febre chikungunya, possuem uma relação positiva, de acordo com Pignatti (2002), há a necessidade da mudança de comportamento da população com relação à correta gestão dos resíduos sólidos. O lixo que é depositado pela população em áreas públicas ou terrenos baldios acaba por aumentar consideravelmente o número de potenciais criadouros de $A$. aegypti (PIGNATTI, 2002).

Por esse motivo é importante que as ações de Educação Ambiental sejam realizadas de forma contínua, e, além disso, mais do que produzir ações pontuais ou momentâneas, sensibilizar a população para adquirir, realmente, novos hábitos. O mutirão foi realizado para fazer uma primeira limpeza, porém todas as ações que o antecederam visavam à continuação da disposição correta dos resíduos sólidos de forma diária.

Os resultados das ações de Educação Ambiental realizadas no município de Condor podem ser observados com a comparação na quantidade de casos de suspeita de dengue que ocorreram no município durante os meses de maior incidência do mosquito. Na Figura 1, apresenta-se os dados retirados do SINAN, para Condor, nos meses de janeiro a junho dos anos de 2016 e 2017.

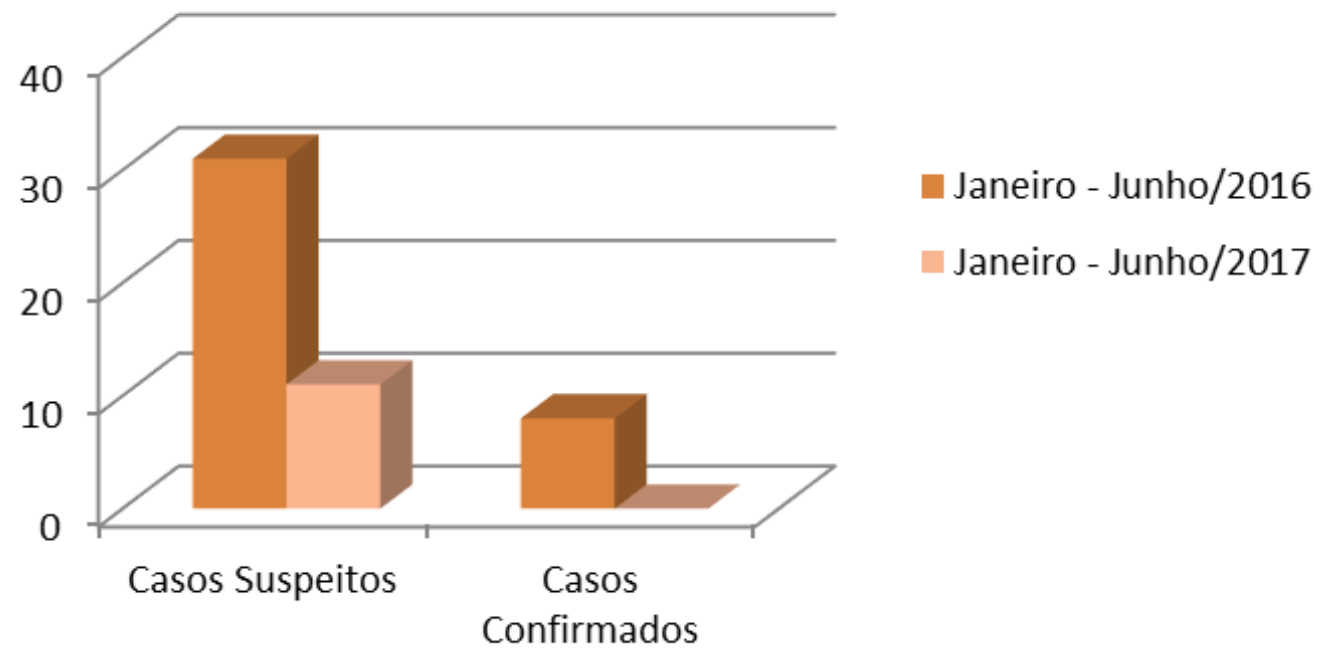

Figura 1: Casos de sintomas de dengue no município de Condor/RS de janeiro a junho dos anos de 2016 e 2017. Fonte: (RAHMEIER, 2017 adaptado de SINAN).

No período de janeiro a junho do ano de 2016, houve o registro de 31 casos suspeitos de dengue, onde o paciente apresentava os sintomas típicos da doença, sendo que destes, oito casos foram confirmados através de exames laboratoriais como dengue. 
No mesmo período, porém no ano de 2017, após as ações de Educação Ambiental realizadas na segunda quinzena do mês de novembro de 2016, no município de Condor, foram registrados apenas 11 casos de suspeita de dengue, e destes nenhum foi confirmado.

Considerando o porte do município com pouco mais de seis mil habitantes, os resultados apresentados pelo SINAN demonstram uma redução significativa nos casos suspeitos de dengue, principalmente pela negativa de casos no período de estudo do ano de 2017, ou seja, após as atividades descritas neste trabalho.

Outro sistema que pode ser utilizado na comparação de dados é o LIRAa, o qual registra os índices de infestação pelo mosquito $A$. aegypti, e mapeia os bairros que apresentam maior incidência de focos do mosquito. $\mathrm{Na}$ Figura 2, estão representados os índices de infestação do $A$. aegypti no município de Condor, retirados dos registros do LIRAa, nos meses de janeiro à junho dos anos de 2015 à 2017.

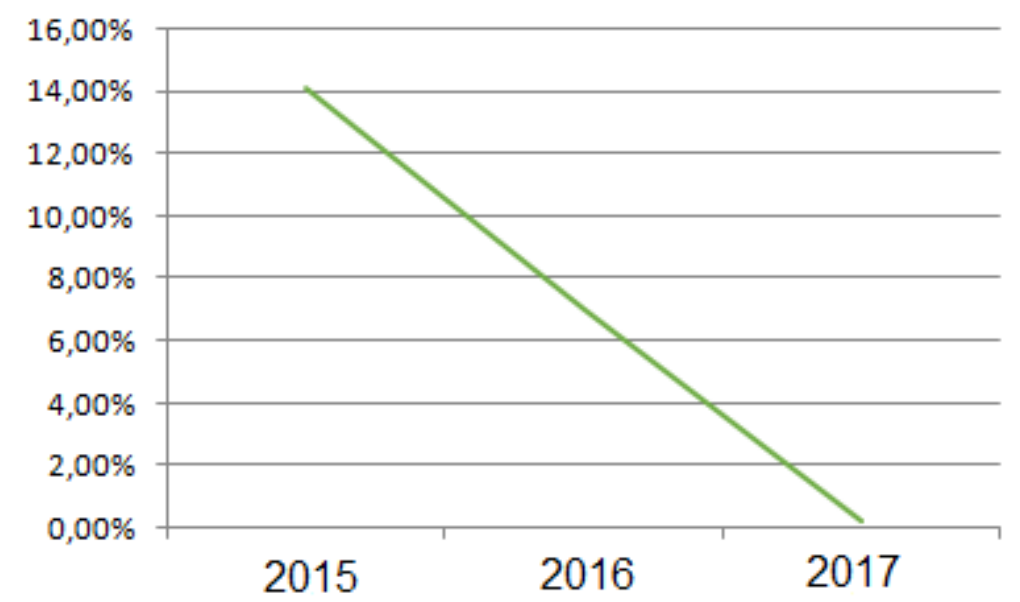

Figura 2: Índice de infestação pelo mosquito A. aegypti no município de Condor/RS no período de janeiro a junho dos anos de 2015 a 2017. Fonte: (RAHMEIER, 2017 adaptado de LIRAa).

Ao analisar os dados do LIRAa na Figura 2, pode-se perceber uma queda considerável nos índices de infestação na área urbana do município, sendo que em 2015, o índice era de 14,1\%, um valor expressivo, considerando que índices acima de $3 \%$, já caracterizam potencial risco de epidemias de doenças transmitidas pelo $A$. aegypti. Em 2016, os índices diminuíram para $7 \%$, mas ainda representavam um grande risco para a população do município de Condor.

Após o período em que foram realizadas as ações de Educação Ambiental, os índices de infestação registrados pelo LIRAa foram de $0,2 \%$, um valor muito expressivo, já que este fica muito abaixo do risco de surtos de doenças causadas pelo vetor $A$. aegypti.

Assim, somados os dados do SINAN e do LIRAa, percebe-se que mesmo o trabalho sendo realizado um mês e quinze dias antes do registro dos 
dados, as ações de sensibilização causaram resultados a longo prazo, e mesmo nos meses em que a temperatura e outras condições climáticas estão favoráveis para a proliferação do $A$. aegypti, não houveram registros confirmados de dengue ou outras doenças transmitidas por esse mosquito, assim como a redução nos focos de deposição de ovos.

Segundo Tauil (2001), a prevenção as doenças transmitidas pelo A. aegypti passa pela importante incorporação de novos hábitos no cotidiano da população e também do poder público. O incentivo e a iniciativa de sensibilização da população são essenciais para que pequenas ações realizadas por todos, sejam compreendidas como vitais na promoção da qualidade de vida.

Portanto, neste contexto, pode-se observar que a Educação Ambiental se configura como uma importante ferramenta, a qual se torna um processo de formação e transformação, permitindo desenvolver saberes e ações voltadas para a melhor qualidade de vida e bem-estar tanto do homem quanto do ambiente.

\section{Conclusão}

As ações de Educação Ambiental realizadas no município de Condor/RS reforçaram a ideia de que uma das principais ferramentas contra o Aedes aegypti, e a prevenção de doenças epidêmicas transmitidas pelo mosquito é a mudança de hábitos. A Educação Ambiental apenas como conceito delimitado aos saberes colocados no papel não causa o efeito desejado de transformação e adoção de novos hábitos.

A realização de palestras sobre o mosquito $A$. aegypti em escolas municipais e estaduais do município se mostrou eficaz, pois o público trabalhado ao longo do período é especificamente aquele que está muito propenso à sensibilização acerca das questões ambientais, ou seja, alunos dos anos iniciais (2 $2^{-a}$ ao $5^{\circ}$ ano) do ensino fundamental.

Iniciar a sensibilização pelos alunos das escolas do município, principalmente dos anos iniciais do ensino fundamental, foi uma importante tarefa, pois estes podem levar os novos aprendizados para seus familiares, assim como adquirir novos olhares e ações com relação ao cuidado com o meio ambiente, pensando não apenas no presente, mas também no futuro.

A promoção da caminhada ecológica com a efetiva participação dos alunos das escolas localizadas na zona urbana do município que, chamando a comunidade a participar do mutirão de limpeza dos pátios, também se mostrou uma excelente estratégia para obtenção dos resultados observados.

A realização do pedágio ecológico nas vias do município para que se alcançasse uma significativa distribuição de saquinhos de lixo para os veículos, comprovadamente é uma ação de Educação Ambiental digna de registro pelo seu alcance. 
A promoção do mutirão de retirada de resíduos sólidos dos pátios e terrenos baldios conseguiu uma efetiva participação dos moradores do município e da empresa que presta serviços de coleta de lixo, com volumes significativos de material recolhido.

Mobilizações que envolvam a comunidade em geral, e que leve informação e principalmente provoque a reflexão quanto a importância de cada indivíduo para a melhoria da qualidade de vida e a prevenção de doenças, assim como impactos ambientais são formas válidas de sensibilização, as quais tornam cada membro da comunidade responsável pelo bem-estar de toda população.

Ao analisar os dados apresentados neste trabalho, observa-se que ações de Educação Ambiental podem promover diferenças positivas de comportamento. Em um município de pequeno porte, estes resultados podem ser alcançados em um curto espaço de tempo, e ter efeito quase imediato.

Pode-se então concluir que a partir do momento em que a população é sensibilizada e começa a ter consciência dos eventuais problemas que o descaso com o ambiente e a má disposição de resíduos sólidos pode causar, e o quão importante é seu papel para evitar as conseqüências desses problemas, fica mais fácil haver uma mudança real de comportamento, assim como o engajamento de mais pessoas à causa ambiental.

\section{Referências}

ABRELPE. Panorama dos Resíduos Sólidos no Brasil em 2015. Disponível em: <http://abrelpe.org.br/download-panorama-2015/>. Acesso em 28 de novembro de 2016.

ABRELPE. Política Nacional dos Resíduos Sólidos - PNRS. 2010. Disponível em:< http://www2.mma.gov.br/port/conama/legiabre.cfm?codlegi =636 >. Acesso em: 28 de novembro de 2016.

CAVALCANTE, K. R. J. L.; et al. Avaliação dos conhecimentos, atitudes, e práticas em relação à prevenção de dengue na população de São Sebastião DF. Brasil, 2006. Com. Ciências Saúde, n. 2, v. 18, 2007. p. 141-146.

DIAS, G. F. Educação Ambiental: princípios e práticas. 1992, 1aㅡ ed. São Paulo: Gaya. 399 p.

FERREIRA, I. T. R. N; et al. 2009. Participação da população no controle da dengue: uma análise da sensibilidade dos planos de saúde de municípios do Estado de São Paulo, Brasil. Disponível em: <http://www.scielo.br/scielo.php ?script=sci arttext\&pid=S0102-311X2009001200015 >. Acesso em: 02 de junho de 2017.

GADOTTI, M. Educar para a Sustentabilidade: uma contribuição para a década da educação para o desenvolvimento sustentável. São Paulo: Editora e Livraria Instituto Paulo Freire. 2009 
INSTITUTO BRASILEIRO DE GEOGRAFIA E ESTATÍSTICA - IBGE. Disponível em: <https://cidades.ibge.gov.br/brasil/rs/condor/panorama>. Acesso em: 28 de novembro de 2016.

JÚNIOR, J.A do N.; BERNARDES, R.S. Estudo epidemiológico da relação entre limpeza pública e a ocorrência do Aedes aegypti. 1999. Disponível em: <http://www.bvsde.paho.org/bvsaidis/brasil20/vii-007.pdf>. Acesso em: 27 de maio de 2017.

LEVANTAMENTO DE ÍNDICE RÁPIDO DE INFESTAÇÃO POR AEDES AEGYPTI - LIRAa - 2005. Brasília: Ministério da Saúde, 2005. Disponível em: $<$ http://portalms.saude.gov.br/>. Acesso em: 08 de dezembro de 2106.

MEDEIROS, A. B. et al. A importância da Educação Ambiental na escola nas séries iniciais. 2011. Disponível em: < http://www.terrabrasilis.org.br/ ecotecadigital/pdf/a-importancia-da-educacao-ambiental-na-escola-nas-seriesiniciais.pdf > . Acesso em: 28 de novembro de 2016.

MIRANDA, M.S.L.; CAPRARA, A.; PEIXOTO, A.C.R.; MOTTA, C.M.V.; SANTANA, R.P. Percepção de atores sociais responsáveis pela gestão de resíduos sólidos no contexto da dengue. 2013. Disponível em: $<$ https://periodicos.unifor.br/RBPS/article/view/2909>. Acesso em: 27 de maio de 2917.

PAIVA, S. A de; SILVA, S. C. S da; e AGUIAR, V. G de. Dengue versus lixo uma problemática no Jardim Nova Esperança. 2012. Disponível em:< https://www.ibeas.org.br/congresso/Trabalhos2012/lll-019.pdf>. Acesso em: 28 de novembro de 2016.

PIGNATTI, M. G. Políticas ambientais e saúde: as práticas sanitárias para o controle do dengue no ambiente urbano. 2002. Disponível em: $<$ http://www.anppas.org.br/encontro anual/encontro2/GT/GT12/gt12 marta pig natti.pdf>. Acesso em: 18 de junho de 2017.

RIO GRANDE DO SUL. Plano Estadual de Saúde 2016-2019. Secretaria da Saúde. Grupo de Trabalho de Planejamento, Monitoramento e Avaliação da Gestão (Org.). Porto Alegre. 2016.

SISTEMA DE INFORMAÇÃO DE AGRAVOS DE NOTIFICAÇÃO - SINAN. Dengue - Notificações Registradas: banco de dados. Disponível em: <http://portalsinan.saude.gov.br/>. Acesso em: 08 de dezembro de 2016.

TAUIL. P. L. Urbanização e ecologia da dengue. Cadernos de Saúde Pública. 2001.

THIOLLENT, M. Metodologia da pesquisa-ação. S.Paulo: Ed. Cortez, 1986.

VALDAMERI A. J. Educação Ambiental: Um Diagnóstico em Escolas Municipais. 2004. 90 f. Dissertação (Mestrado em Engenharia de Produção) Programa de Pós-Graduação Universidade Federal de Santa Catarina, Florianópolis. 